\title{
50 Years of \\ WIRTSCHAFTSINFORMATIK: Moving on to New Shores...
}

\author{
DOI 10.1007/s12599-008-0006-3
}

\section{The Author}

Prof. Dr. Hans Ulrich Buhl

University of Augsburg

Department of Information Systems Engineering \& Financial Management Universitätsstraße 16

86135 Augsburg

Germany

hans-ulrich.buhl@wiwi.uni-augsburg.de

This article is also available in German in print and via http://www.wirtschafts informatik.de: Buhl HU (2008) 50 Jahre Zeitschrift WIRTSCHAFTSINFORMATIK: Auf zu neuen Ufern.... WIRTSCHAFTSINFORMATIK. doi: 10.1007/11576-0080110-5.
50 years ago - in 1959 - the first issue of the journal elektronische datenverarbeitung (electronic data processing) appeared with the objective to close the gap in scientific research publications with respect to the "practical application of computers in business" (n. a. 1959, p. 3). In those days probably neither the editorial staff nor the publisher or the readers expected that this journal under the name ofWIRTSCHAFTSINFORMATIK would advance to the most important scientific journal of this young field in the German-speaking countries, to the field's central publication, and to its only internationally acknowledged German-language journal over the last five decades. By means of this anniversary issue we want to honor that success - and the journal's 50th anniversary.

Based on the previously outlined success and on the occasion of this anniversary, what would be more obvious than to strategically set the journal's course? What would be more obvious than to align the journal with the increasing importance of international research, to establish a unique platform for our rather design scienceoriented research, and thus to address all techno-economically oriented readers and authors?

The purpose of this issue is two-fold: It is both an anniversary issue and the first issue of a comprehensive, bilingual triple-strategy addressing researchers and practitioners. This strategy has been planned and implemented by the editors and publishers during the last two years. From this issue on, an English-language e-journal named "Business \& Information Systems Engineering - The International Journal of WIRTSCHAFTSINFORMATIK" will be published under the responsibility of an extended international editorial board. It will appear simultaneously, with identical content as an enhanced WIRTSCHAFTSINFORMATIK and will be available via SpringerLink. With support of the scientific editorial board, Gabler Publishing will also start a German-language journal called Wirtschaftsinformatik \& Management (WUM), which is geared to practitioners in the field of business and information systems engineering (BISE).

By means of this anniversary issue we would like to present the diversity of the journal's and discipline's dynamic development as well as the implications on research and practice of the last five decades. We would also like to give future-oriented and trend-setting impetus. Therefore we present a highly selective spectrum of exclusive articles.

At the beginning, there are two contributions concerning the journal's development. The former editors-in-chief Norbert Szyperski, Peter Mertens, and Wolfgang König discuss the major developments of their tenures from a present-day perspective as interview partners. Moreover, Ulrich Hasenkamp and Peter Stahlknecht analyze the journal's major developments and focuses as regards content.

Then, seven invited contributions by renowned persons from research and business practice follow. Hermann-Josef Lamberti and Matthias Bueger discuss the lessons learned from using IT in the banking industry with Deutsche Bank AG as example, starting from punch card machines through to industrialization and outsourcing of IT-services. Martin Jetter, Gerhard Satzger, and Andreas Neus illustrate how ITbased innovations affect business models, organizations, and enterprise cultures with the transformation of the IBM Corporation to a globally integrated and serviceoriented enterprise as example. Günter Müller recapitulates the development of the Internet, looks for analogies to the development of BISE, and poses the question of the field's future orientation. Rex Chen, Kenneth L. Kraemer, and Prakul Sharma provide well-founded insights into Google as one of the most successful Internet search engines and advertising platforms and its objective to become the world's first in- 


\begin{tabular}{|c|c|c|c|c|}
\hline Section & Author(s) & Title & Year & Nominating editor(s) \\
\hline Research Paper & Erwin Grochla & $\begin{array}{l}\text { Corporate Information Systems Engineering and Business } \\
\text { Information Systems Engineering as a Necessary Application- } \\
\text { Oriented Extension of General Computer Science }\end{array}$ & 1969 & $\begin{array}{l}\text { Ulrich Hasenkamp, } \\
\text { Norbert Szyperski }\end{array}$ \\
\hline Research Paper & Henning Kagermann & Distribution of Integrated Business Applications & 1993 & Peter Mertens \\
\hline Research Paper & Leena Suhl & Decision Support Systems for Production Planning in Airlines & 1993 & Peter Mertens \\
\hline Research Paper & Werner Sinzig & $\begin{array}{l}\text { New Trends in the Architecture of Standard Software } \\
\text { Illustrated by the Example "Controlling" }\end{array}$ & 1995 & Peter Mertens \\
\hline Research Paper & $\begin{array}{l}\text { Hans Ulrich Buhl, Volker } \\
\text { Visser, Andreas Will }\end{array}$ & The Virtualization of Banking Industry & 1999 & Peter Mertens \\
\hline Research Paper & Georg Disterer & $\begin{array}{l}\text { Individual and Social Barriers for Composing } \\
\text { Knowledge Repositories }\end{array}$ & 2000 & Wolfgang König \\
\hline Research Paper & Jens Dibbern, Armin Heinzl & $\begin{array}{l}\text { Outsourcing of Information Processing in Small } \\
\text { Business: Testing a Multi-Theoretical Causal Model }\end{array}$ & 2001 & Hans Ulrich Buhl \\
\hline Research Paper & $\begin{array}{l}\text { Stefan Holland, } \\
\text { Werner Kießling }\end{array}$ & User Preference Mining Techniques for Personalized Applications & 2004 & Wolfgang König \\
\hline State of the Art & Stefan Kirn & Cooperating Intelligent Software Agents & 2002 & Peter Buxmann \\
\hline State of the Art & Arnd Klein, Helmut Krcmar & $\begin{array}{l}\text { Electronic Meeting Systems Paradox - Obstacles to Deploy } \\
\text { Efficient Techniques and How to Overcome These }\end{array}$ & 2003 & Peter Buxmann \\
\hline State of the Art & $\begin{array}{l}\text { Martin Bichler, Alexander } \\
\text { Pikovsky, Thomas Setzer }\end{array}$ & $\begin{array}{l}\text { An Analysis of Design Problems in } \\
\text { Combinatorial Procurement Auctions }\end{array}$ & 2005 & Peter Buxmann \\
\hline Catchword & $\begin{array}{l}\text { Nicolas Bissantz, } \\
\text { Jürgen Hagedorn }\end{array}$ & Data Mining & 1993 & Elmar Sinz \\
\hline Catchword & Stephan W. Eder & Green Computers & 1994 & Elmar Sinz \\
\hline Catchword & $\begin{array}{l}\text { Bernd Jahnke, Hans-Dieter } \\
\text { Groffmann, Stephan Kruppa }\end{array}$ & On-Line Analytical Processing (OLAP) & 1996 & Elmar Sinz \\
\hline Catchword & Dietrich Cerny, Hartmut Pohl & Trusted Third Parties and Security Infrastructures & 1997 & Elmar Sinz \\
\hline
\end{tabular}

formation utility. Arnold Picot and Oliver Baumann describe the relation between BISE and organization theory. Matthias Jarke does the same with respect to computer science. Last but not least, August-Wilhelm Scheer outlines how BISE links science and entrepreneurship.

Two selected contributions from the first issue of elektronische datenverarbeitung from 1959 point out that the necessity of integrative thinking - which is constitutive for today's BISE - was already clearly fixed in the minds of visionaries. John Diebold pleads for well-founded university education and extra training alongside work in the field of BISE. Karl Heinz Kettner postulates the use of information and communication technology to enable integrated workflows and to make enterprises more competitive.

Subsequently, we present six best papers of the last 50 years. These were chosen by the (former) editors-in-chief and section editors from the sections Research Paper, State of the Art, and Catchword between 1959 and 2008. Due to their excellent scientific quality, the felicitous synthesis of scientific questions and their practical application, or the early dealing with visionary topics, these papers serve as models for future research. For lack of space, only some articles can be printed. These are: "Corporate Information Systems Engineering and Business Information Systems Engineering as a Necessary Application-Oriented Extension of General Computer Science" (Grochla 1969), "Distribution of Integrated Business Applications" (Kagermann 1993), "Outsourcing of Information Systems Functions in Small and Medium Sized Enterprises: A Test of a Multi-Theoretical Model" (Dibbern and Heinzl 2001) from the section Research Paper, "An Analysis of Design Problems in Combinatorial Procurement Auctions" (Bichler et al. 2005) from the section State of the Art as well as "Data Mining" (Bissantz and Hagedorn 1993) and "Green Computers" (Eder 1994) from the section Catchword. A complete overview of all nominated papers - without any ranking - can be found in Tab. 1.

An interview of Alan R. Hevner conducted by Robert Winter on "Design science" and the current Calls for Papers for the issues $1 / 2010$ and $3 / 2010$ conclude this anniversary issue.
The previously mentioned triple-strategy raises a number of questions. These are: What objectives does the strategy pursue? Which components are covered by this strategy and how is the present journal WIRTSCHAFTSINFORMATIK affected? Which key messages are meant to be conveyed by the English-language title?

The triple-strategy's primary objective is to align the journal WIRTSCHAFTSINFORMATIK with the requirements of an increasingly international research and to position it as one of the international top journals. At the same time it is necessary to convey the field's and journal's strengths to the international world without neglecting their position in the German-speaking countries.

- Two important strengths of the German-language field BISE are the fruitful and mutual exchange with business practice as well as the pluralistic, rather design science-oriented, and interdisciplinary research approach. The former becomes particularly evident in the fact that at most economic faculties BISE departments are the largest 
ones and those with the highest amount of third-party funds. Here, we have real competitive advantages compared to information systems (IS): due to their strongly behaviorist approach - which unquestionably fulfills high rigor requirements - IS research results are usually less applicable in practice or partially even insignificant. In contrast, we solve problems in the real business world with high relevance. Thus, good scientific BISE publications not only fulfill rigor but also relevance criteria at a high standard. They are practice-oriented in a way that IS research still lacks and that has been postulated by IS colleagues for a long time (e. g. Davenport and Markus 1999; Rosemann and Vessey 2008). In an exaggerated way one could say: despite some attempts towards design science most IS colleagues probably conduct behavioral research almost exclusively because in a strongly decreasing market chairs are appointed according to one's publications and the behaviorist approach (still) dominates international rankings.

- Another strength of BISE is the university education conducted by almost 200 chairs and professorships in the German-speaking countries. By means of an interdisciplinary orientation at the borderline between science and business practice, BISE graduates are highly qualified for further activities in both science and practice. Thus the demand for these graduates is high. It is not unusual that enterprises get involved financially and/or by means of additional courses (e. g. project seminars) in many BISE study programs in order to get to know later graduates and highly qualified students in an early stage. Consequently, these excellent career perspectives make BISE highly demanded by school graduates. For instance, at the University of Augsburg there were approx. seven applications per place for the BISE bachelor study program introduced in winter 2008/2009. In general, BISE enrollment remained constant in recent years and even grew moderately. In contrast, IS enrollment decreased significantly - with few ex- ceptions - and dropped by approx. $75 \%$ between 2000 and 2006 (Nickerson 2007). Furthermore, according to a current study, only $50 \%$ of the leading North American business schools include obligatory courses on (management) information systems in their MBA programs today (Navarro 2008). Therefore, BISE has reasons to not only overcome its weaknesses but also to further improve its strengths in a self-confident way and by no means to sacrifice these strengths on the altar of a misunderstood international adaptation.

- Another strength is the journal's double-blind - which for instance has only been standard of the international top journal Information Systems Research since March 2008 (Sambamurthy 2008) - as well as constructive and rapid review process. Each manuscript is pre-reviewed by the editor-in-chief with support of highly skilled colleagues. If promising, manuscripts are evaluated - usually after a first revision - by at least three international experts from science and practice (usually there are two from science and one from practice) in multiple rounds to publication maturity. Involving reviewers from practice also shows the significance of relevance. What we aspire is to extract the scientifically interesting core and to identify valuable contributions by constructive suggestions in the sense of "journal editors as diamond-cutters rather than gatekeepers" (Straub 2008, p. vii). This method avoids type Il errors ("rejection of a valuable contribution"), which have been discussed by Detmar W. Straub (2008) and Carol Saunders, the current and former editors-in-chief of MISQ. In contrast to other top journals, one review round usually takes less than two months due to the commitment of the former editors-in-chief and the entire editorial board. As a result, we eliminate the insecurity with the authors and create incentives for cumulative research with good and constructive interaction. Papers are only rejected if it is foreseeable that they will not meet the journal's requirements of rigor and relevance even after several rounds. Unfortunately, this happens with more than $70 \%$ of all contributions. Nevertheless, we usually receive positive feedback concerning our constructive and continuous review process, which finally leverages the discipline - even if these contributions are then published in other journals.

In order to achieve these objectives, enhance our strengths, and proclaim them internationally, the triple-strategy consists of the three journals:WIRTSCHAFTSINFORMATIK, BISE, and WUM.

- WIRTSCHAFTSINFORMATIK will continue to appear bimonthly with special issues and multi-thematic issues as print version. Due to its stronger scientific orientation, the journal's content focuses on the scientific sections BISE - Research Paper and BISE - State of the Art as well as on the sections BISE - Profile, BISE - Discussion, and BISE Catchword, which are also interesting for international researchers. The other former sections can either be found at our Internet portal http://www.wirtschaftsinformatik. de and/or will migrate to WUM in a slightly adapted form.

- From this issue on, BISE appears as an e-journal simultaneously and with the identical content as the German-language WIRTSCHAFTSINFORMATIK - in the sense of a oneto-one translation. Besides http:// www.wirtschaftsinformatik.de and http://www.bise-journal.org, the journal is available via SpringerLink (http://www.springerlink.com), the world's largest online library for science, technology, and medicine. Market shares of SpringerLink developed in such a positive way during the last years that the major part of international researchers in most countries, like the US, Canada, Australia, Scandinavia, and Eastern Europe, can easily access BISE from their universities or research facilities already today. To advertise the journal as quickly as possible, this first issue will appear with a high and later reduced - print run, which will be distributed to national and international multipliers. To support our international editorial board we were able to recruit some 
highly reputed colleagues. They are introduced in the section BISE - Editorial Notes. Manuscripts to both scientific journals can still be submitted in German or English. In the case of acceptance they will be translated in close cooperation with the authors and a professional team of translators, thus always appear bilingually, and gain a significantly higher international visibility than before.

- WUM - also appearing for the first time together with this anniversary issue - constitutes the link to the German-speaking BISE practitioners. It has its own editorial staff at Gabler Publishing and an advisory board composed of top-class researchers and practitioners. Based on the model of the Harvard Business Review, the objective is to supply BISE practitioners even better than before with well-founded, professional, and magazine-like information highly relevant for business practice. For this purpose, WUM will offer independent and up to date editorial contributions as well as practice-oriented management summaries of selected and accepted contributions of the scientific journals with reference to the original publications.

No matter which journal a reader obtains: Every subscriber of one of the three journals has full access to our entire German- and English-language content and of course to the online archives of all three journals via our newly designed Internet portals (http://www.wirtschaftsinformatik.de or http://www.bise-journal. org).

A major question in the course of this triple-strategy was the one concerning an appropriate title for the English-language and the connected key messages. With Business \& Information Systems Engineering (BISE) we convey the already discussed design science approach via the term "engineering". Moreover, we signalize that we address all techno-economically oriented readers and authors as target groups. By means of the term "business" we address colleagues who approach BISE questions from a more business administration perspective. With "information systems" we reach the growing number of international IS colleagues who are interested in both rigor and relevance. With "engineering" we additionally address German- and Englishspeaking industrial engineers and colleagues of applied computer science who deal with BISE-related topics. The title's ambivalent reading addresses economically oriented (business and business engineering), IS- and BISE-oriented (information systems and information systems engineering), and engineeringoriented (business engineering and information systems engineering) readers and authors, the disciplines' borderlines and thus the entire techno-economically oriented scientific community.

To sum up: By means of this triad of WIRTSCHAFSTSINFORMATIK, BISE, and WUM we address the German-speaking BISE community in business practice and science in an improved way. At the same time, we cater for the entire international techno-economically oriented scientific community!

On behalf of all former editors-in-chief and those of this anniversary issue - our colleagues Hasenkamp, König, Mertens, and Szyperski - as well as on behalf of the entire editorial board I would like to thank all authors. By means of their submissions they contributed to create an issue worthy for both the $50^{\text {th }}$ anniversary of WIRTSCHAFTSINFORMATIK and the starting of the triple-strategy. Moreover, we would like to thank all reviewers who supervised the contributions in several rounds in a very professional manner. We would like to thank both groups for their patience and understanding they showed while dealing with the demanded revisions and our tight time restrictions. Special thanks also go to the editorial staff for their excessive extra work mainly supporting the translation progress. I also thank Robert Winter who - as responsible editor - has shaped the triple-strategy from its beginnings and also won multiple industry partners as well as international editors. Finally, I would like to thank all authors, reviewers, and editors of the last 50 years' issues: The journal WIRTSCHAFTSINFORMATIK would not have been so successful without you.

Special thanks - on behalf of the editorial board and Gabler Publishing - also go to our industry partners Allianz, Commerzbank, IBM, McKinsey, SAP, and T-Labs who made this anniversary issue and the triple-strategy possible by means of their generous financial support.
Our last words address the community: The success of the last 50 years in the German-speaking countries was only possible because of the commitment of all members. This also applies to the triple-strategy. Therefore, we ask everyone of you to positively develop this strategy together with us, to multiply it in your personal networks, and thus to make it become known. Only then will we succeed nationally and internationally in the future!

Prof. Dr. Hans Ulrich Buhl

\section{References}

Davenport TH, Markus LM (1999) Rigor vs. relevance revisited: response to Benbasat and Zmud. MIS Quarterly 23(1):19-23

Navarro P (2008) The MBA core curricula of topranked U.S. business schools: a study in failure. The Academy of Management Learning and Education 7(1):108-123

Nickerson RC (2007) IS enrollment decline. Summary of ISWorld responses. http://online.sfsu. edu/ rnick/isenroll.pdf. Accessed 2008-09-04 na (1959) Elektronische Datenverarbeitung. Fachberichte über programmgesteuerte Maschinen und ihre Anwendung. elektronische datenverarbeitung 1(1):3-4

Rosemann M, Vessey I (2008) Toward improving the relevance of information systems research to practice: the role of applicability checks. MIS Quarterly 32(1):1-22

Sambamurthy V (2008) Editorial note. Information Systems Research 19(2):125

Straub DW (2008) Thirty years of service to the IS profession: time for renewal at MISQ? MIS Quarterly 32(1):iii-viii 


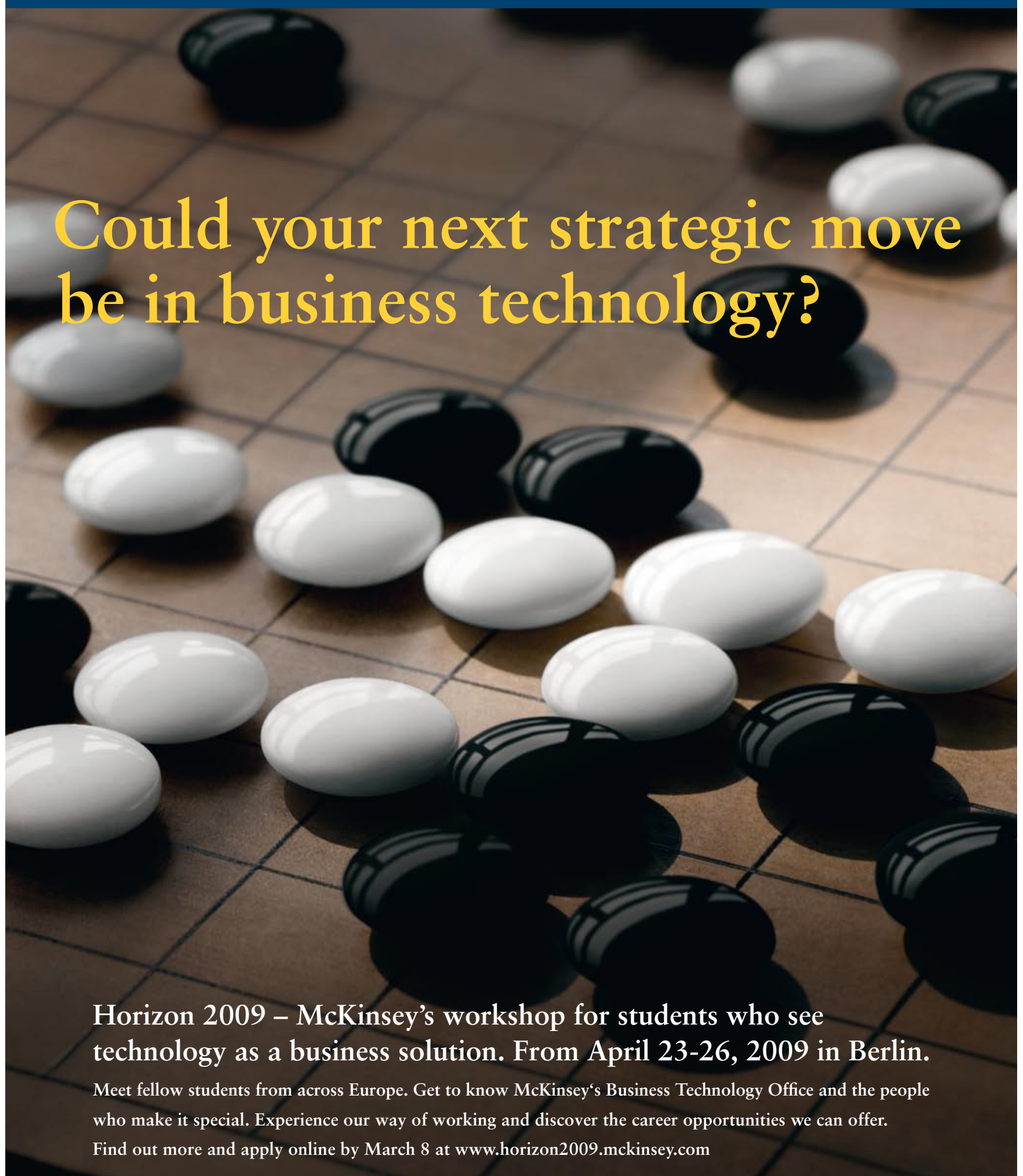

\section{McKinsey\& Company}

